\title{
Evolving technologies require educational policy change: Music education for the 21st century
}

\author{
Renée Crawford \\ Monash University, Australia
}

\begin{abstract}
There is growing discussion among education and government authorities on rethinking education in the 21 st century. This increasing area of interest has come in response to the evolution of technology and its effect on the future needs and requirements of society. Online applications and social networking capabilities have accelerated in popularity, revealing their potential. The recognised benefits of technology for the use of music education have resulted in collaborative projects and learning and teaching that is not constricted by walls or location. Music education can be accessible to all young people through a combination of social media, blogging and interactive creative musical activities to engage students in all locations, including rural and remote areas. In this 21 st century classroom, music education includes online resources, digital learning, in-school workshops, online master classes and live concert streaming where a range of musical styles are explored. This article explores the learning and teaching outcomes of Project Music $X$, an online music education project designed to fill an important gap in the provision of music education programs in regional and remote schools using a range of web 2.0 technologies. Technology in this context does not only align with the thinking of young people, but also provides a platform for students in remote and rural areas to engage with high quality music education and performance experiences that they would otherwise not have access to.
\end{abstract}

\section{Introduction}

Rethinking teaching and learning pedagogy for education in the 21 st century has surfaced in response to the growing and changing needs and requirements of society. Education and government authorities have noticed the significant disparity between what occurs in the classroom and what occurs in real-life contexts (Crawford, 2007, 2009b). This has been identified in a number of recent Victorian curriculum documents, such as the Victorian Essential Learning Standards (Department of Education and Early Childhood Development, n.d.), which emphasises development of lifelong learners and the importance of real-life learning contexts, and more currently in the Australian national curriculum. The term "School $2.0^{\prime \prime}$ is being used by Steve Hargadon, who runs a wiki titled School 2.0 Wiki (http://school20.wikispaces.com/), to describe the shift in thinking about what schools will look like in the future. He describes three major factors at the core of this discussion:

1. New collaborative computer technologies which include distance learning, free and open source software, videoconferencing and read/write web.

2. A changing economy that has transitioned from the industrial age through the information age to the current digital age, where employers value and require people to have a different skill set.

3. New technologies giving birth to a culture that is transparent, multidimensional and collaborative allowing open discussion about many aspects of society, particularly education.

In responding to this shift in thinking and finding a practical way to enhance music education and performance experiences for young people, there are an increasing number of high quality online resources and applications available to teachers and students. A notable resource, unfortunately recently made unavailable was themusicpage.com, a company which was dedicated to the proposition that the world's best performances and the world's best teachers should be available to anyone, anywhere at any time. The founder and managing director explained that their mission was simply, "To change the musical world by connecting musicians and educators to a global audience" (Collinson, 2012). They used TMP web that would stream both live and archived performances to anyone wishing to view them. They could also connect students and teachers over the Internet using both simplex (one-way) and duplex (two-way) communication technology. This innovative use of technology is continually evolving. 
The Sound Exchange was the website hosted for the educational activities undertaken by the Philharmonia Orchestra, a vision originating from the research carried out by Olivia Lowson in 2000 (Philharmonia Digital Projects, 2012). While temporarily unavailable, this interactive website has been evolving for several years and will continue to develop its rich resources, sample libraries, forums, live concert webcasts, online composer workshops, new music education videos and online and offline events. Initial funding was supplied by the Arts Council of England in 2002, which allowed for the commission of Professor Hugill who began working on the original core resources. The website and project is now supported by the David and Elaine Potter Charitable Foundation. Their mission is to, "continue to add new resources, run cutting-edge interactive projects and push the boundaries of what is possible" (Philharmonia Digital Projects, 2012).

The final exemplar is an interactive website on "Music Improvisation" by the Berklee College of Music titled Berklee Shares, which has been evolving since 2003 (Berklee College of Music, 2012). Some of its major features are online lessons and performances. Other popular music topics that they cover are production and technology, music business and song writing and arranging. Using technology in the context applied to these examples of online resources not only aligns with the thinking of a digital society and young people, but it makes music and music education from all over the world more accessible.

Despite the availability of these high quality resources for teaching and learning, such as the exemplars described here, there remain many examples of music education in Australia being approached in a traditional model of schooling (Crawford, 2009b). That is, using technology as a one-way information base, not an interactive information exchange. This paper explores the recent teaching and learning outcomes of Project Music X, an online music education project designed to fill an important gap in the provision of music education programs in regional and remote schools using a range of web 2.0 technologies. Used within a blended learning context this project not only identifies the benefits of such an approach, but highlights the need for pedagogical and policy change.

Pedagogical change needs to occur at teacher and school level and policy change needs to occur at school and government level. The expected integration of technology in the Australian curriculum is undisputedly clear (Southcott \& Crawford, 2011; Australian Curriculum and Assessment Reporting Authority [ACARA], 2012a). The Australian Curriculum, Assessment and Reporting Authority (ACARA, 2012a) state that students should:

Develop ICT capability as they learn to use ICT effectively and appropriately to access, create and communicate information and ideas, solve problems and work collaboratively in all learning areas at school, and in their lives beyond school. The capability involves students in learning to make the most of the digital technologies available to them, adapting to new ways of doing things as technologies evolve.

In order for this to occur, the education technology policy restrictions need to change accordingly and allow access to interactive information exchange technology platforms and many applications and resources currently unavailable to schools due to access restrictions. This is especially true for many simple music resources that should be utilised for music education. YouTube is a simple example of this. The educator's YouTube does not always provide access to extensive music content, due to the nature of what may be attached to some of that content. Project Music $X$ is a positive example, which identified that when restriction to these platforms and resources are raised, learning is engaging and emulates reallife learning or authentic practice. This highlighted the underlying issue that exists for many Australian schools. The focus needs to shift from access restrictions for students, to better education of cyber practices for students and teachers. Support for teachers should include the development of critical understanding on how to appropriately facilitate and monitor learning activity within these cyber platforms.

It is important to note that while the premise for this project (due to the funding requirements) was to provide students within rural and remote schools access to high quality music education opportunities and experiences, the results support a case for the adoption of this blended learning approach in all schools. The implementation of the National Broadband Network and increased internet reliability makes this accessibility more of a possibility. 


\section{Evolving technologies require educational policy change}

For several years, people of all ages around the world have embraced technology, the Internet and other technological devices that encourage inherently open and social participation. In Australia, social networking has accelerated in popularity over the past couple of years in line with the rest of the world according to the company comScore, which is a United States based global leader in measuring the digital world and digital intelligence (Radwanick, 2009). This surge has come in support of a change in the way the Internet or web is both perceived and used. Downes confirms that this change has been in transition for several years as he explained in 2005:

Enter Web 2.0, a vision of the Web in which information is broken up into "microcontent" units that can be distributed over dozens of domains. The Web of documents has morphed into a Web of data. We are no longer just looking to the same old sources for information. Now we're looking to a new set of tools to aggregate and remix microcontent in new and useful ways.

The Web has shifted from just being a medium in which information is transmitted and consumed, to a platform where content is created, shared, remixed and repurposed. People are no longer merely using the Web for reading books, listening to the radio or watching television, but are having conversations consisting of a visual and multimedia vocabulary. Web 2.0 does not only look like a network, but behaves like one. By definition, web 2.0 is used to describe "applications that distinguish themselves from previous generations of software by a number of principles. These new, Web 2.0, applications take full advantage of the network nature of the Web" (Ullrich, et al. 2008:705). This change from a read-web medium to a platform for read-write-web fulfils Berners-Lee (1999) original vision of the Web.

While there is evidence of societal acceptance and requirements for the way technology is used and interacted with, web 2.0, social networking and various online multimedia are still considered inappropriate in the education sector. "Research shows convincing examples of using Web 2.0 services for learning...the relationship between Web 2.0 technology on the one hand and teaching and learning on the other hand are still rare." (Ullrich, et al., 2008 p. 705). This disparity occurs due to the education sector discussing such technology in terms of their school policy cyber safety strategy, where concerns of site blocking and cyber-bullying overshadow the benefits of its use. While schools have a responsibility and fundamental duty of care to students which makes site blocking and monitoring web content a necessary component of school policy, so too is educating and skilling our young to contribute and be active participants of society. The world has moved from the agricultural age through the industrial age and into the information age at an exponential rate. This is arguably the most significant change ever experienced in human history (Huitt, 1999; Toffler, 1981, 1990; Pilzer, 1990). As a result of the industrial revolution in the 19th century, education transformed from apprenticeship to universal schooling. Collins and Halverson (2009) explain:

In the apprenticeship era, most of what people learned occurred outside of school. Universal schooling led people to identify learning with school, but now the identification of the two is unravelling. All around us people are learning with the aid of new technologies (p. 1).

The information age laid the foundations for the current digital age. There is an increasing use and reliance on digital technologies in this era and it is having a profound effect on the way that people, especially young people, access knowledge, interact, create, collaborate and essentially learn. This needs to filter through to educational settings if learning and teaching is to occur in a contemporary and relevant way that replicates real-life and authentic practice.

In addressing education pedagogy it is significant to ask how this new technology changes the epistemologies of what may or may not be taught in schools. While this may be beyond the scope of this research, a first step in pedagogical change is to first evaluate the implications of such technology, which requires an understanding of the very basics of this technology. Once this knowledge and critical media literacy is achieved, education policy and school policy can change to encompass the needs and requirements of society in the digital age. Teachers require appropriate education and support to change their pedagogy accordingly. Project Music $X$ is an online music education project that demonstrates a 
positive example of what can be achieved when teachers are provided with the necessary support and information to change their pedagogy. Project Music $X$ began in 2010 and identified some of these requirements and highlights the advantages of embracing new technology for learning within a safe and teacher facilitated environment. While it has been noted that technology will not replace the need for good teachers (Rosenberg, 2001), online learning is an important development in education today. A combination of traditional and face-to-face instruction with online learning has resulted in a concept known as blended learning, which is widely used (Digolo, Andang'o, \& Katuli, 2011).

From a pedagogical perspective, blended learning aims to incorporate the most effective aspects of faceto-face classroom learning experiences with comparatively as good mobile and online learning experiences. This allows:

- An increase in learning outcome measures and lowering of attrition rates compared to fully online courses (Dziuban, Hartman, \& Moskal, 2004).

- An opportunity for students to practise technology skills in navigating online course materials and creating their own digital content for assessment.

- An increase in student to teacher and peer interaction through the use of communication tools like discussion forums, blogs and shared web content on the electronic whiteboard.

- The ability to reserve face to face time for interactive activities, such as higher level discussions, small group work, debates, demonstrations, or in-class activities.

For students, the appeal of blended learning includes:

- $\quad$ Flexibility and the freedom to learn anytime, anywhere.

- It is student-centred, which includes some level of control over the pace of their learning. Difficult concepts can be reviewed as often as necessary.

- More engaging content that they can create and use their own initiative and networks to shape (for example, collaborating with other students from different schools on musical compositions).

- The opportunity to engage and draw on expertise that would otherwise not be available to them without costly travel, such as in the case of music education: virtual conferencing with high level musicians and composers, virtual excursions to concerts, musical events and overseas historical or culturally significant landmarks.

This paper explores the use of blended learning in music education, where the developments have been modest compared to other disciplines (Southcott \& Crawford, 2011). In accordance with ethical requirements, pseudonyms have been employed to preserve the anonymity of the organisations, teachers, students and schools involved in the project; this includes preventing the disclosure of their location.

\section{An interactive online music education project}

Project Music $X$ is an online music education project designed to fill an important gap in the provision of music education programs in regional and remote schools using a range of web 2.0 technologies. Three aims were devised for the project:

1. To provide students within rural and remote schools access to high quality music workshops.

2. To facilitate the use of online music technology and engage students with developing online music compositions and soundscapes.

3. To build capacity within these schools to enable music education and the use of online music technology to continue beyond the completion of the workshop.

Project Music $X$ is a purely remote delivery program as the project manager explained:

While some arts organisations run great regional education programs, a school in a remote or rural area is never going to have the same kind of opportunities for students to visit and experience elite quality concerts, theatre and other performances. Likewise, access to elite arts education programs is also difficult. With the technology that is available right now, almost any school in Australia could give their students at least a taste of that experience (Crawford \& Project Manager, personal communication, May 21 2010). 
The project utilised new technologies to enhance learning experiences, which are relevant to real-life, that these students would otherwise not have access to.

It had been identified that regional and rural schools and communities with disadvantaged student populations are a key area of need for the provision of music and arts based programs. In such a context, music and the arts were used as a vehicle to engage young people in low socio-economic areas and provide opportunities for these students that they would normally not have access to. Music, creative arts or generalist classroom teachers would facilitate the program. Students develop music composition skills using a piece of audio software called Audacity (http://audacity.sourceforge.net/). This fast multi-track audio editor and recorder has features that include envelope editing, mixing, built-in effects and plug-ins. Students create their own compositions and share their work on the Project Music X website. A key element of the project is the use of a blog allowing students and teachers to share, collaborate and comment on their compositions. A teacher from one of the participating schools has indicated that, "the feedback was rather amazing. It's something that as a teacher I never actively sought, until I started using web 2.0. The kids just seem to do it naturally". New communication technologies provide remote access to city based musicians as a supplement to the work achieved in class. Online video conferencing workshops are run with expert musicians from various professional orchestras and bands. The online music workshops are webcast from the studios in the main city. Through the use of online classroom software Elluminate, the students are able to listen to elite musicians and then ask questions and make comments by typing into the chat window. Elluminate unifies technologies such as video and web conferencing, phone, instant messaging, learning management systems and social networks to ensure that learning collaboration is fast and efficient. Avrhami (2010) explains that this new approach called "Unified Learning Collaboration" (ULC):

ULC addresses the changing needs of today's academic institutions and training organisations to make teaching and learning more self-enabled and interactive, while providing cost savings and rapid return on investment. This unique approach supports the creation of a comprehensive infrastructure for learning that includes "people, processes, learning resources, policies, and sustainable models for continuous improvement" identified by the latest U.S. National Educational Technology Plan.

The impact these experiences are having on the students is invaluable, with teachers confirming immediate increased levels of student engagement and interest.

\section{Technology resources}

Some of the greatest challenges facing educators are access to technological resources and the ability to use technology effectively with limited time for professional development opportunities. The technological applications used for the Project Music X are sourced with both capacity building and user simplicity in mind. The project manager explains further, "The most important thing to explain about the technology side of the Project Music X project is the simplicity. All the software we used was off the shelf and either free or already purchased by the DEECD for the use of schools." (Crawford \& Project Manager, personal communication, May 21 2010). From existing licences the Department of Education and Early Childhood Development (DEECD) is able to supply the Elluminate virtual classroom software that is used by the students for the online music workshops. As previously explained, students create their compositions using software called Audacity. This software is free and open-sourced which many schools already have installed and utilise.

A primary issue with technology that the project has encountered concerns bandwidth. The simplest way to define bandwidth is the speed at which data is transferred. Sometimes bandwidth is also used to refer to the maximum capacity or the fastest that a connection can move data. The project manager explains, "The live video conferencing did stretch the bandwidth capacity of some schools, but hopefully this will become less of an issue." (Crawford \& Project Manager, personal communication, May 21 2010). The other side of this issue to consider was that schools were charging their students for internet usage. Due to the Project Music $X$ requiring a large amount of bandwidth per student, this resulted in some students paying extra for access to the project or being locked out because they had no credit left. The DEECD have since made the decision that students should not be charged for bandwidth. This was a positive outcome to enhance an effective music education project. 


\section{Method}

The primary purpose of the research conducted was to measure the impact that the project was having on both the teachers and the students involved. It is appropriate to suggest that young people in contemporary society are competent technology users. Therefore, the primary aim was not to find out if students could use the technology, but assess their learning through their interest, engagement, progression through the online learning modules, uptake of an instrument and monitored usage patterns (whether students were logging on to the website in addition to when they used it in class). It is realised that a longitudinal approach to measuring these identified categories over time would have been beneficial, particularly given that many external and internal factors influence music and instrumental learning, thus requiring monitoring over time. While this is noted as a limitation of this study, there is still significance in the results to justify consideration.

A mixed method approach to this research was taken consisting of participant surveys, semi-structured interviews with the Project Manager and statistics generated from project technicians that monitored the online activity. To avoid interruptions to the project, it was important that the survey used for the teachers and students was designed in a completely nonintrusive way and regarded as an assessment or progress tool, rather than a research instrument. This ensured that the research and evaluation component of the project were both reliable and valid. In accordance with ethical requirements all project participants had consented to the research being conducted, but it had a double purpose for them. Consonant with the commitment to the ethical standards, it was also ensured that because teachers were granted access to students' responses for the purpose of assessment and reporting, that no sensitive data was collected. The survey questions were framed to capture both valuable quantitative and qualitative data.

Results were collected over the duration of a one year period in the form of online survey data from both the students and teachers utilising Project Music X. Collection points occurred three times during the year to capture pre, middle and post opinions and progress. This also allowed the assessment of learning to be measured against interest/engagement and program usage. It was also an aim to capture the confidence levels of the teachers using the technology to facilitate music learning.

Using a combination of Google analytics and another tracking program (not disclosed by the organisation employed), the technicians working on the project were able to monitor student usage, which was more than just the basic log-on activity. They could identify specific student activity based on what students clicked. Monitored online activity was also collected to coincide with the three data collection points of the survey. This further ensured the reliability of the data collected.

For the purpose of this article a sample size of 20 Year 7 and 8 classes consisting of 20 teachers and 440 students is used. As previously mentioned, to protect the anonymity of the participants and schools involved in the project, the locations have not been disclosed. However, the aim of the project was to provide vital music education programs in regional and remote schools using a range of web 2.0 technologies.

\section{Results of a blended learning approach using Project Music X}

The following series of graphs demonstrates part of the baseline data collected to capture the confidence level of teachers prior to their use of Project Music X, then half way through the year and finally at the conclusion of the school year. As explained, a representative sample used for the purpose of this article is limited to 20 teachers. 


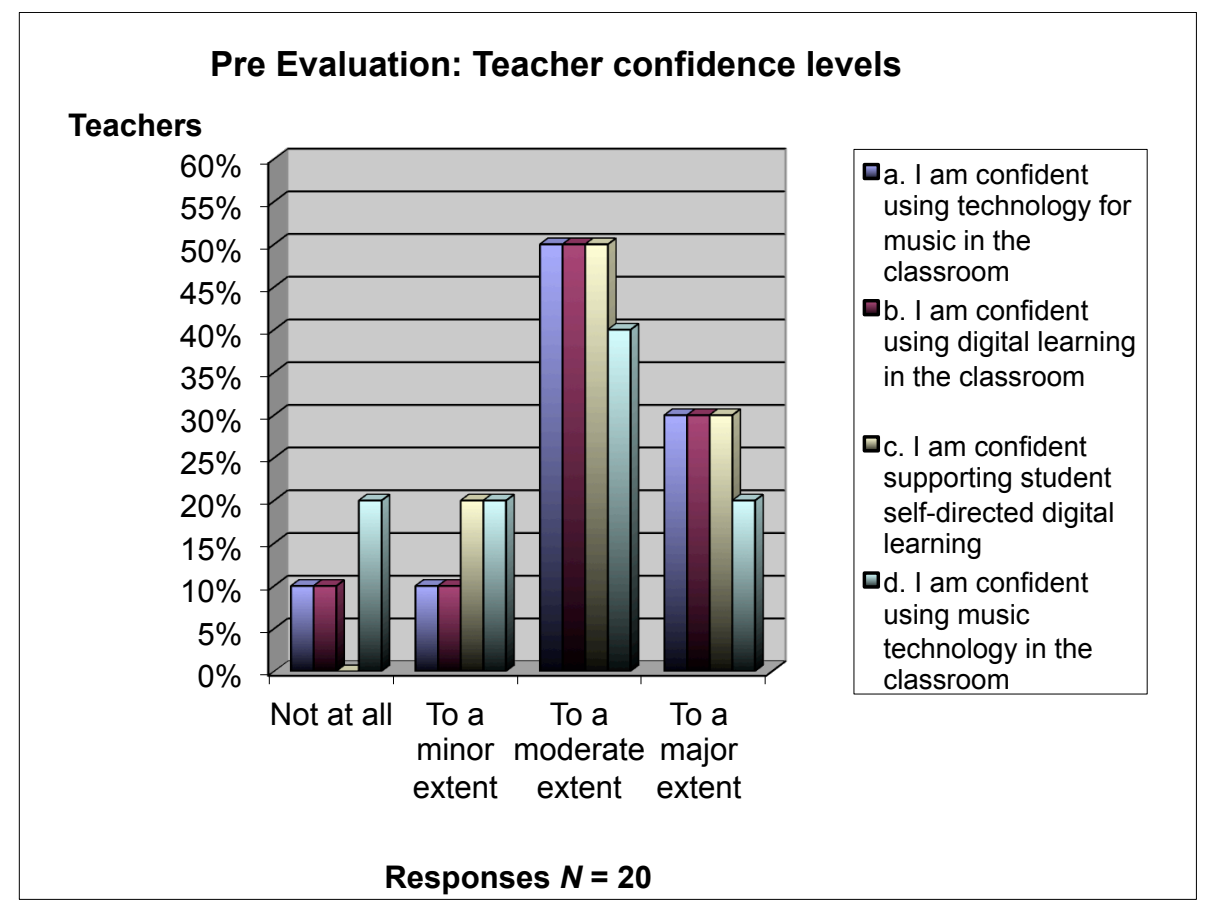

Figure 1. Pre evaluation: Teacher confidence levels.

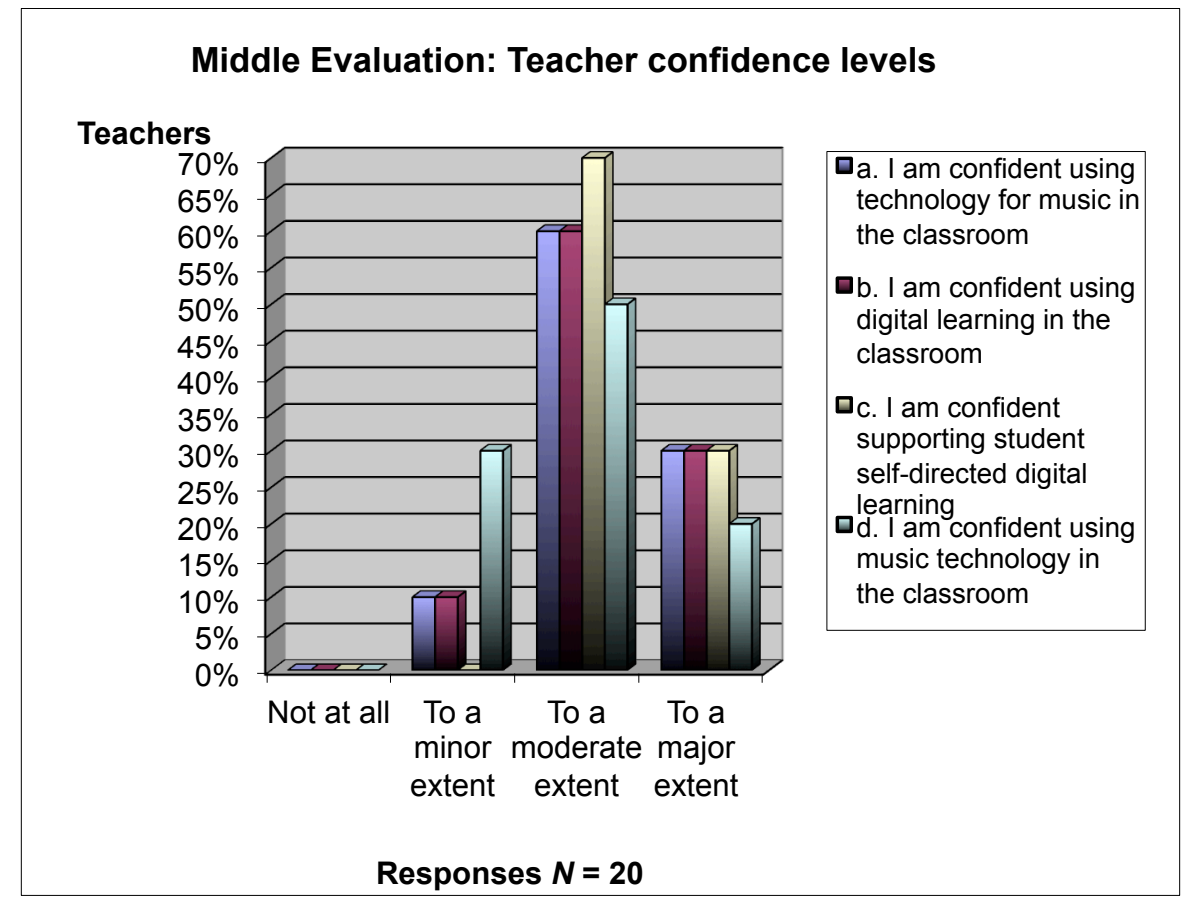

Figure 2. Middle evaluation: Teacher confidence levels. 


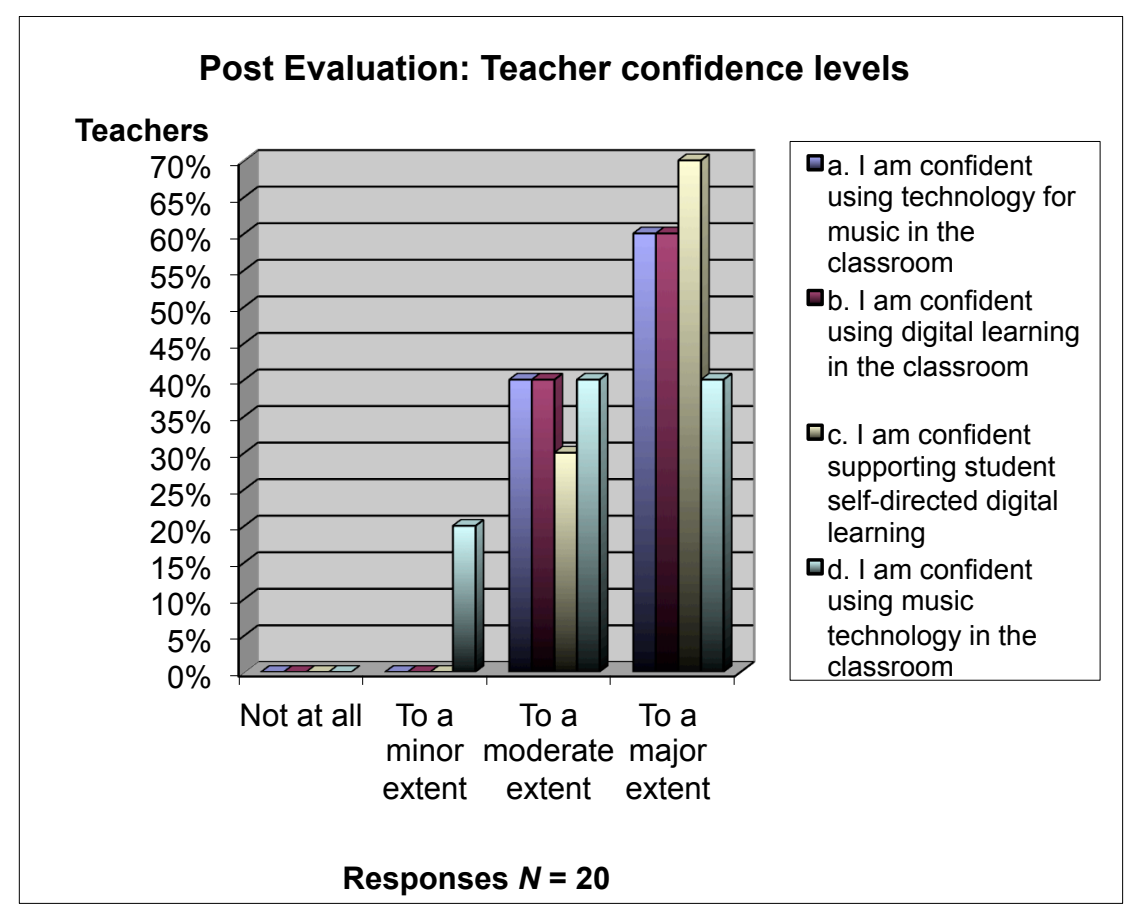

Figure 3. Post evaluation: Teacher confidence levels.

The graphs in Figures 1 to 3 show a steady increase of confidence in all four categories as the year progresses. This can firstly be attributed to the simplistic fact that the more teachers used the technology and were familiar with the digital blended learning environment, the more confident they became. Secondly, this project had a comprehensive support network and mentoring system available for facilitating classroom teachers. Much previous research has outlined that one of the factors in the reluctance of teachers using technology in the classroom is feeling unprepared or that they lacked training (Crawford, 2009b). Teachers expressed that the design of this project negated this issue. Not only were they using technology in an innovative and multidimensional way, but they could see the immediate value for their students' learning.

Teachers were also asked whether they thought that the blended learning approach impacted on their students' learning progress throughout the year. The following graph demonstrates that teachers were in overall agreement that the learning of their students progressed consistently and that the blended learning approach did in fact have a positive impact by enhancing their students' learning. 


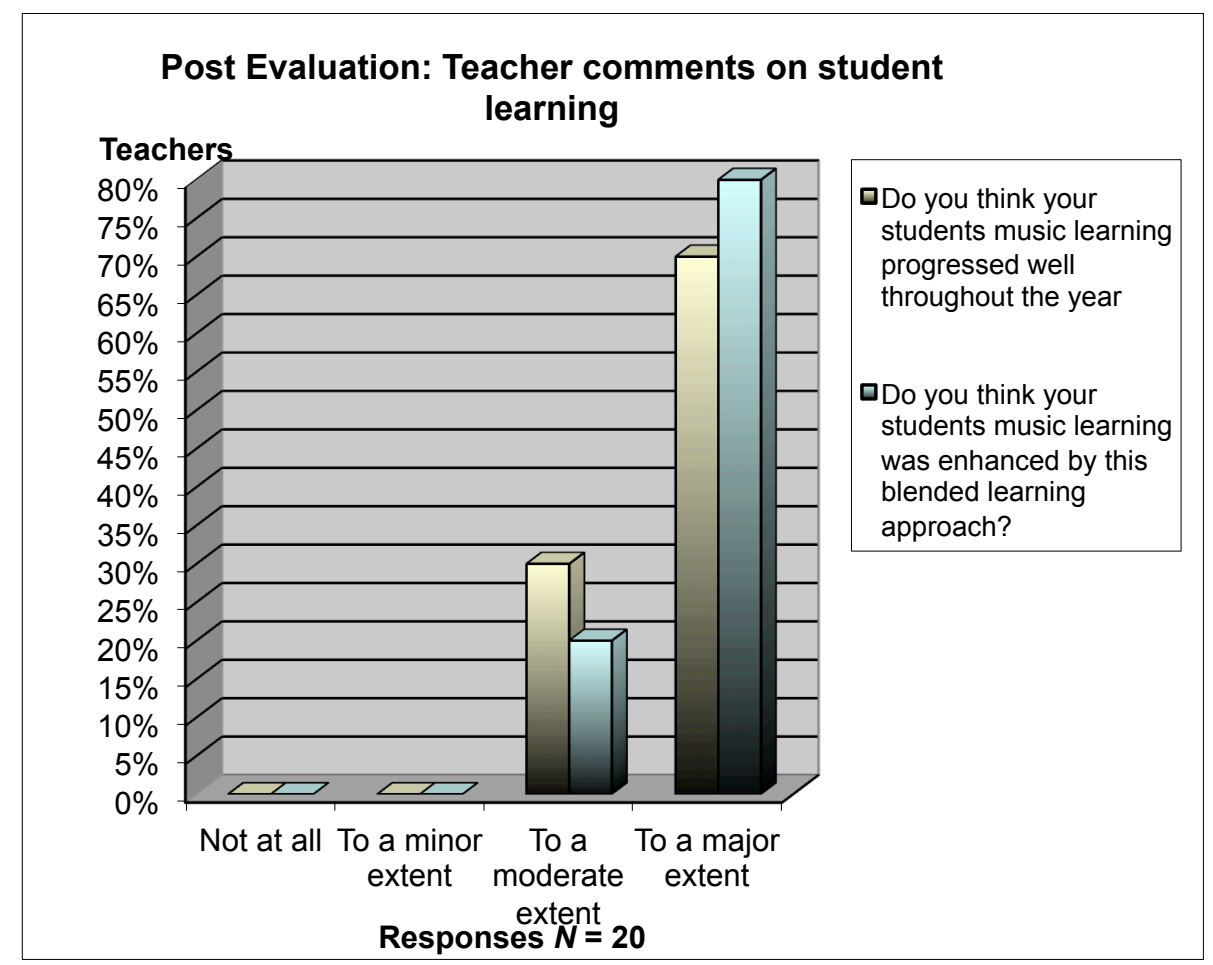

Figure 4. Post evaluation: Teacher comments on student learning.

Data was also collected from the students participating in the project. The representative sample used for the purpose of this article considers only the students in the classes of the teachers discussed. The student sample totals 440 individuals from Year 7 and 8 classes. The following series of graphs outlines the results for the identified measurement categories for the students at the three data collection points throughout the year.

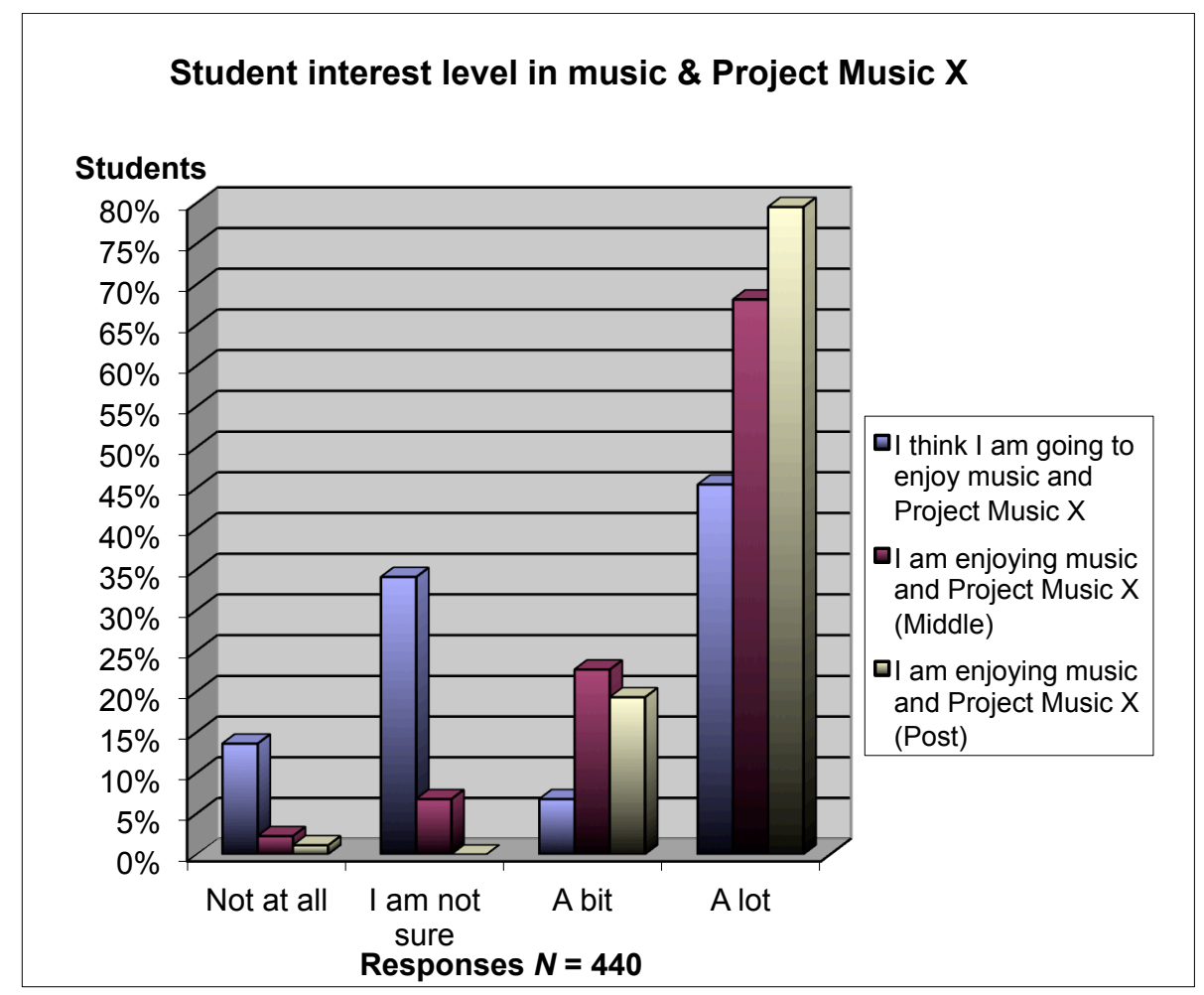

Figure 5. Student interest level in music and Project Music X. 
The graph in Figure 5 demonstrates a steady increase in student interest and enjoyment of Project Music $\mathrm{X}$ overall as the year progressed. It is interesting to note how the uncertainty about the program at the beginning of the year changes to a positive, even for those students who were convinced they would not enjoy it at all.

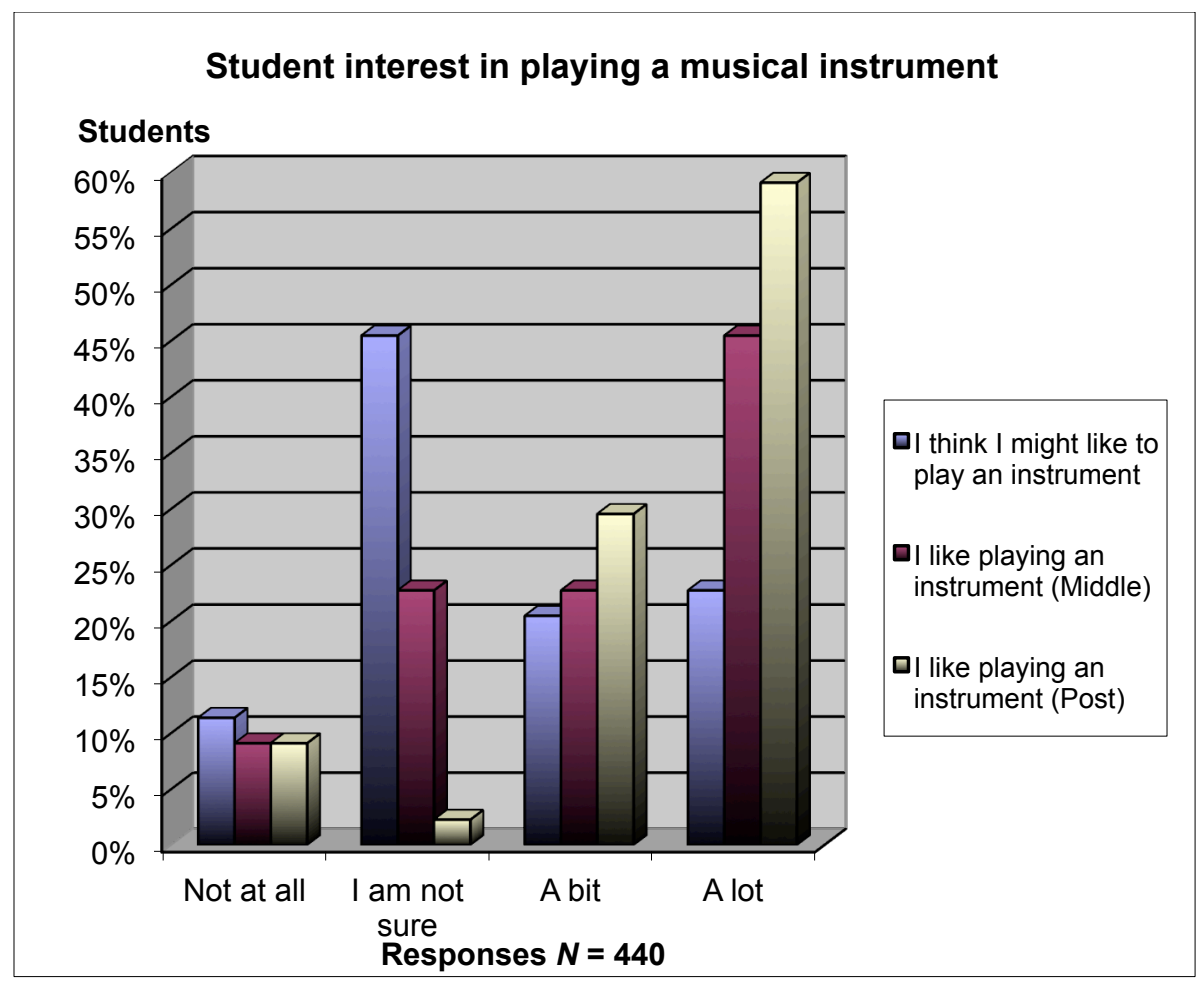

Figure 6. Student interest in playing a musical instrument.

Figure 6 clearly displays a steady increase in interest for playing an instrument as the students progressed through the year. The students' feedback also supported that they were both interested and engaged in music learning through this blended learning approach. The following examples of student comments highlight this:

Student 1: "I really like being able to talk to the musicians from the orchestra. They were so funny. They answered all my questions, even the silly ones."

Student 2: "It was good that we could talk to other students in other schools about what we were doing. It really helped me. Like [Tommy] from [Secondary School] gave me ideas about the song I was writing. It made it heaps better."

Student 3: "I didn't think I would like music or playing an instrument, but I really like drums. Maybe I could get good and be like Dave from the Foo Fighters."

Student 4: "I like being able to talk to my friends after school about the things I am working on for music, it really helps to be able to share your ideas."

Student 5: "I like that the practice videos are set at different speeds. Sometimes it's hard to get a riff, but having it shown how to play it slow then faster and faster helps heaps."

Students 6: "I have always wanted to write a song, but can't read music. I have written a pretty cool song and I didn't even need to know music. But I can a bit now too, because it shows you the notes as well as the loops."

Student 7: "One of my favourite things about music I think was seeing the performances. They were live and we got to talk to the performers afterwards sometimes too. We don't have things like that [here] so it is the first time I have seen this. It would be even better in the hall, but this is pretty good, because we wouldn't see it all."

Student 8: "Being able to work with the music experts online was amazing. They gave me good ideas and helped me". 
These qualitative comments demonstrate engagement with learning in an authentic way. The exemplars indicate how Project Music $X$ effectively accommodates different learning styles, musical skill levels and interests.

Such interest and engagement is further supported by the increase of student instrument uptake throughout the year. The graph in Figure 7 shows that by the middle of the year, $68 \%$ or 300 students had taken up an instrument. At the conclusion of the year, 410 of the 440 students involved had taken up an instrument. Therefore, $93 \%$ of students participating in the project made a decision to take the opportunity that they were presented with and learn an instrument by the conclusion of the year. This is a notable increase of 110 students who chose to take up an instrument from the middle to the end of the year.

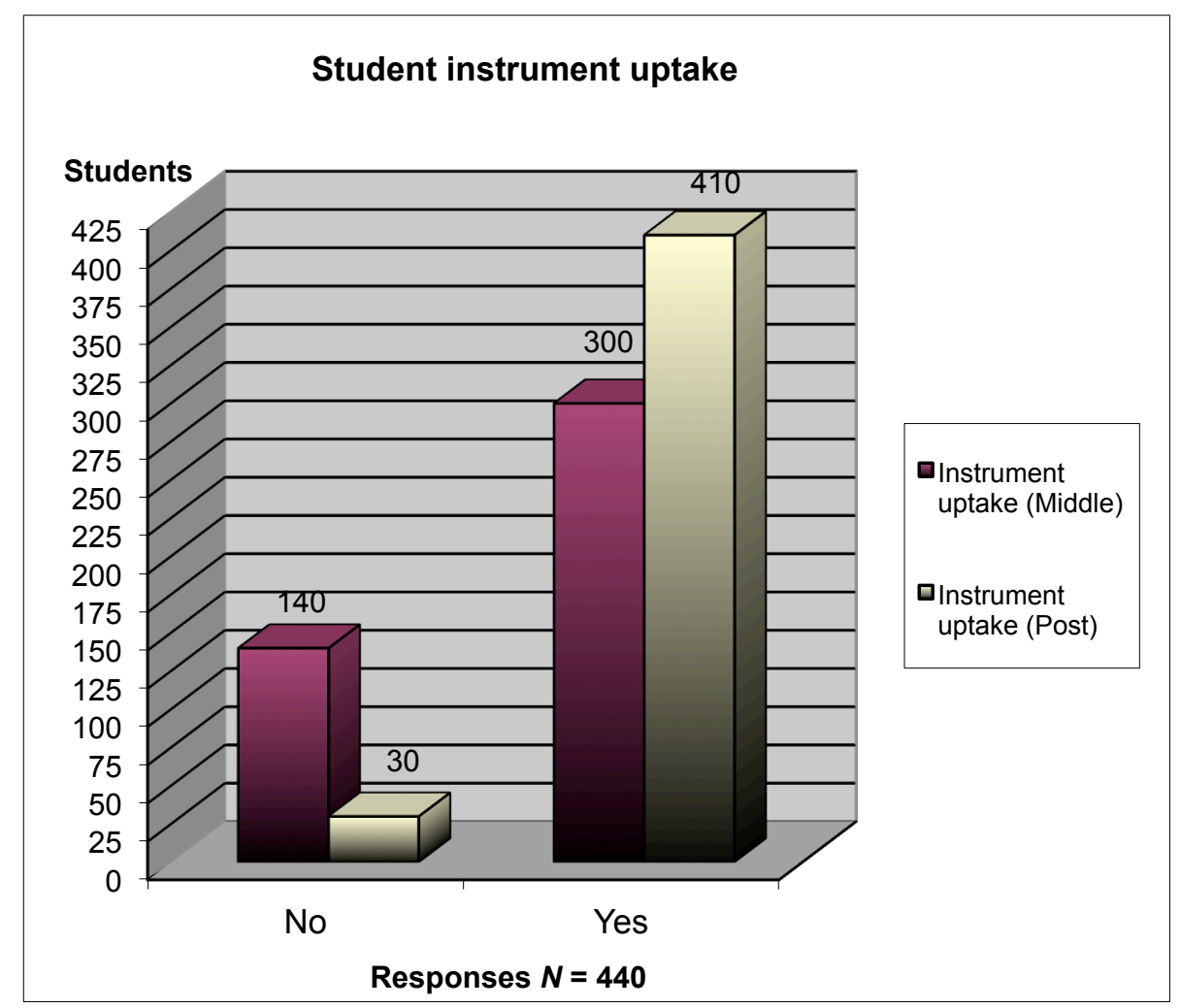

Figure 7. Student instrument uptake.

The types of instruments students had the opportunity to learn as an instrumental music option through the project were guitar, keyboard, percussion and ukulele. The cost of supplying instruments to the participating schools was factored into the budget of the project as the schools involved would not have been able to provide such resources to their students.

Figure 8 demonstrates what the students said their usage of Project Music X was outside of school time. 


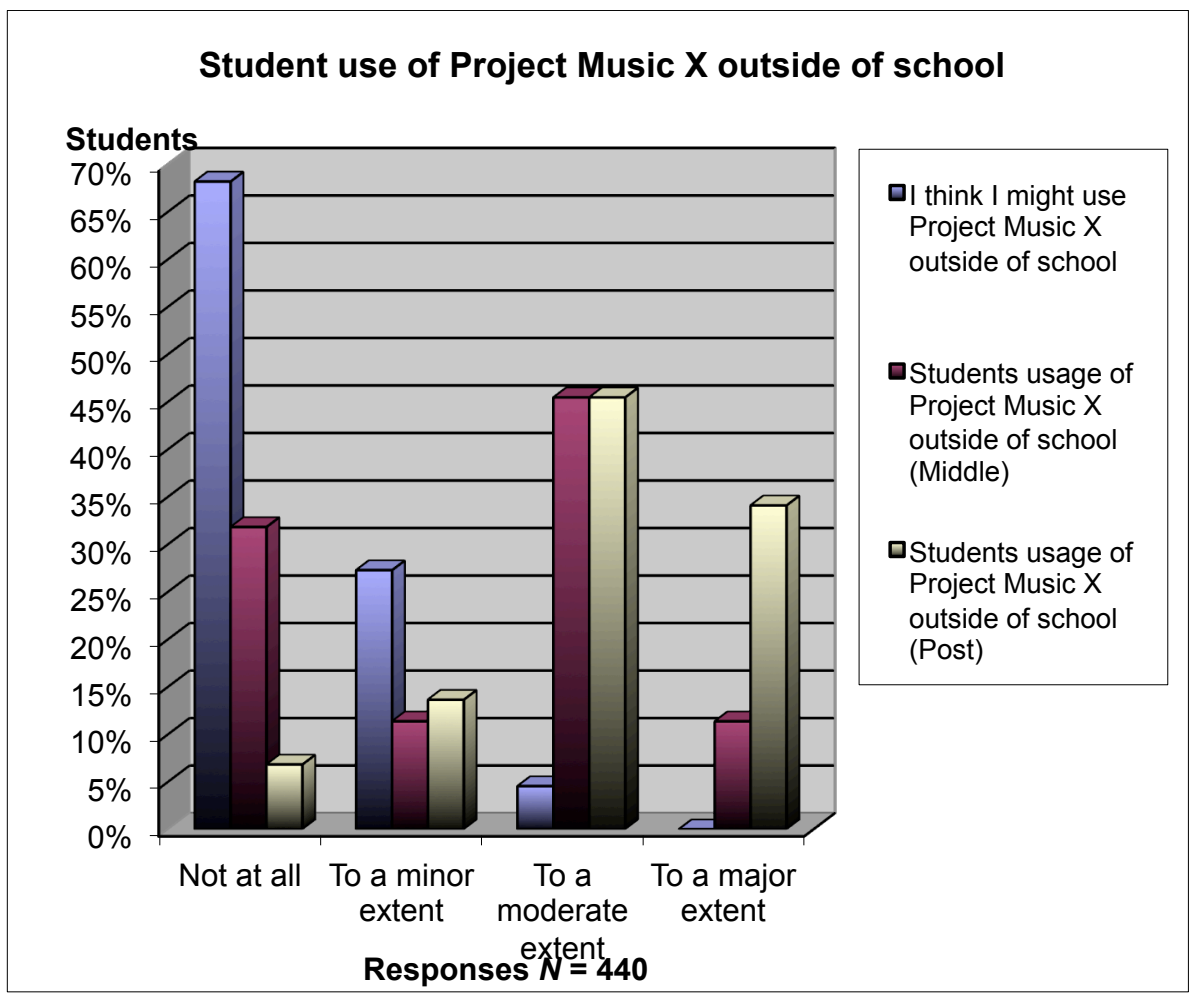

Figure 8. Student use of Project Music X outside of school

There is a clear major shift from students not thinking that they would ever use Project Music $X$ outside of school time at the beginning of the year, because it is "work", to actually making a conscious decision to use it for their own learning, watching concerts, having private lessons and for participating in discussions with peers. This was not a case of finishing off class activities or lessons for homework. As stated in the methodology, using a combination of Google analytics and another tracking program (not disclosed by the organisation employed), usage was monitored by the technicians involved. They could identify specific student activity based on what students clicked, not just a basic log of activities. To provide an indication of the quality of the monitored usage, the parameters provided included activities that accessed specific learning activities or engaging in forum discussion specifically about music or the module tasks in some way. This was possible as the site was moderated. Therefore, the following monitored usage graph consolidated these parameters and was collated to coincide with the three data collection points. It is recognised that there are limitations to capturing only a snapshot of data at certain time points, but this has been triangulated with other data collection at the same time points. 


\section{Monitored student usage of Project Music X outside of school time}

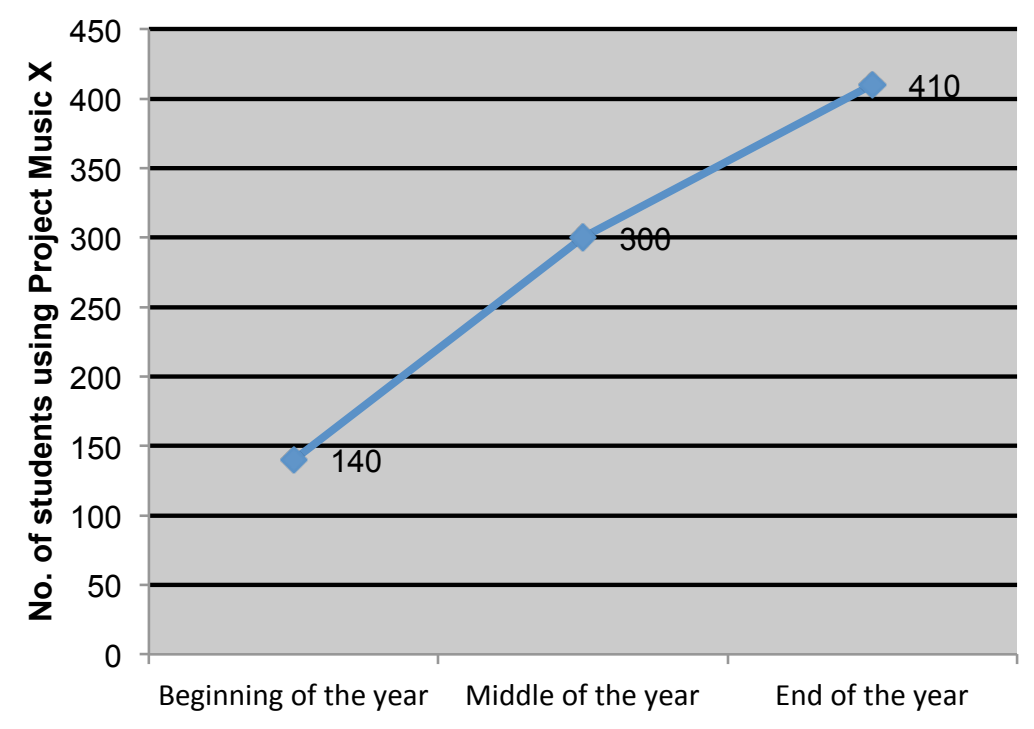

Figure 9. Monitored student usage of Project Music X outside of school time.

This data illustrated in Figure 9 was also valuable in comparing what the students indicated their usage to be, and the actual monitored usage affirms student responses. There is a notable increase from the beginning of the year when only 140 students or $32 \%$ said they think they would use Project Music $X$ outside of school time. Half way through the year the figures indicated that 300 students or $68 \%$ were using it outside of school time and this further increased to 410 students or $93 \%$ by the conclusion of the year. This is not only supported by the steady increase in student interest and engagement in Figure 5 , but the fact that many of the students decided to learn an instrument. Needing to access the lessons and practise sessions would increase outside of school time usage. Classroom teachers also encouraged use of the online resource outside of school. The value of this project was that it enhanced the music learning of students both in and out of school, through the use of technological tools that young people have become accustomed to using when communicating, socialising, playing and working. Both teachers and the community supported this innovation as all the activities were conducted in a safe and monitored environment.

Out of the 10 learning modules set during the course of the year, it is generally expected that by the middle of the year students will have progressed to the end of module 5, and then work through to module 10 by the end of the year. This is a self-directed student learning approach so that students may take as much time as they require and the teacher will facilitate where necessary to assist students along. There are extension activities in each module for advanced students and in general they cater for different learning levels. Modules were designed in alignment with the Victorian Essential Learning Standards (VELS) as a curriculum framework. The progression points from VELS were also used to assist in distinguishing module levels and age appropriate content (Victorian Curriculum and Assessment Authority [VCAA], 2009a, 2009b). It was decided that monitoring students' progression through the modules in terms of which learning module they have completed according to the expected time frame would be valuable for two reasons. The first is in verifying and providing a basis for modifying module levels according to student learning levels and the second is as a way of providing the classroom teachers opportunities to assess their students' progress.

The following table shows that most students finished up to the expected module by the middle of the year. This is an extremely positive outcome that was certainly assisted by the fact that the students 
enjoyed learning music using the blended learning approach and Project Music X. A total of $98 \%$ of students finished all modules by the end of the year.

Table 1

Learning Modules completed by students at two assessment points

\begin{tabular}{llllllllllll}
\hline & \multicolumn{7}{c}{ Learning modules } & & & & \\
& 1 & 2 & 3 & 4 & 5 & 6 & 7 & 8 & 9 & 10 \\
\hline Completed by middle of year & & & & & & & & & & \\
Number of students $(\mathrm{N}=440)$ & - & - & - & 40 & 380 & 20 & - & - & - & - \\
$\begin{array}{l}\% \text { of students } \\
\text { Completed by end of year }\end{array}$ & - & - & - & 9 & 86 & 5 & - & - & - & - \\
Number of students $(\mathrm{N}=440)$ & - & - & - & - & - & - & - & - & 10 & 430 \\
$\%$ of students & - & - & - & - & - & - & - & - & 2 & 98 \\
\hline
\end{tabular}

Although this project was only measured over the duration of a year, the importance of these results confirms that blended learning approaches to teaching and learning music need serious consideration.

\section{Discussion and conclusion}

In contrast to the way technology was used in Project Music X, Southcott and Crawford (2011) assert that, "Music education curricula in Australia seem to perceive ICT as offering a different set of tools to support music education, much as a new set of percussion instruments might do" (p. 124). This limited understanding of the use of ICT simply as a tool is further identified by Mark and Madura (2010) as computer aided instruction (CAI). In this approach the potential benefits of technology in music teaching and learning are reduced simply to assisting with aural training and the acquisition of notational skills. Further, Crawford (2009a) confirms that in the United States,

Music technology and computer technology in the form of computer-aided instruction was frequently used in a highly-structured classroom setting. This learning environment, which used simulated and guided instruction, promoted intensive skill development (p. 154).

In contrast, Mills and Murray (2000) assert that technology could enhance music lessons when students worked primarily as musicians. This alternate approach was also supported by Bray, Brown, and Green (2004) who suggested that, ICT has the potential to enhance creativity, facilitate learning, and encourage exploration and independent learning. Technology used in this setting can be identified as computer aided learning (CAL). This approach to using technology in the classroom was first adopted by music teachers in the United Kingdom where they, "supported a curriculum promoting creativity and independent learning. This less skill-intensive approach was considered more suitable for general music classes and encouraged problem solving" (Crawford, 2009a, p. 154). This view that technology be used in music education for the purpose of either CAI or CAL alone is no longer relevant to contemporary music education paradigms. Results from the impact of the music education project and other similar studies (Hitchcock 2008, 2009; Hitchcock, Cunio, Harvey, \& Chircop 2010; Borota, 2011) provide growing evidence that technology should be used in a blended learning approach that promotes teaching and learning in a collaborative and holistic way.

There are many factors that need to be considered in the 21 st century classroom and it is important that they align in order to provide an environment conducive to effective learning. Teresa Dillon (2007) points out that the dearth of understanding that exists concerning creative and collaborative possibilities of the use of technology in music education affects "the training of teachers, the design of music technologies and the development of meaningful music activities" (p. 118). Project Music X was designed to provide a platform for relevant, meaningful and contemporary music activities that removed the classroom walls and brought the outside world into the classroom and vice versa. The musical activities are authentic with opportunities for students to collaborate with professional composers, musicians, their peers, teachers and workshop artists. Dillon and Brown (2007) see such programs as increasing "access to authentic musical 
experiences". As an extension to this, Crow (2006) explains that various free music technology applications used in current society by young people, such as Itunes or Windows Media Player can be regarded as a manifestation of collaborative possibilities, where students might make personal musical choices with regard to listening to music and can "share their musical choices" (p. 124). The final factor addressed in the project was that classroom teachers were also offered continuous mentoring and a support network for any issues. This was to help increase their skills and confidence in what was for some teachers an unfamiliar environment to teach in.

Choi and Piro (2009) state that, "modern youth are connected to technology like no previous generation" (p. 32). The teaching and learning landscape has changed and music educators need to stay abreast of developments in technologies and their use by students. Mark and Madura (2010) agree that music teachers need to question the relevance of "their instruction to increasingly technological youth" (p. 140). If this issue is not addressed, music education will become irrelevant, predated and due to its declining importance, may result in a drop in student enrolments causing it to be excluded from the curriculum. This study demonstrated that classroom teachers were enthusiastic about using blended learning in their classroom, particularly with the mentoring they received. While results demonstrated that their skills and confidence levels increased as the year progressed, they expressed that seeing the engagement and progress of their students made it even more valuable. Cain (2004) concurs that classroom practices should "keep pace with the world outside" (p. 219). Technology provides an important platform in the ability for music educators to close the divide between their students' experiences of music in the classroom and outside. Part of what the results from this study show was an increase in online activity both in and out of the school setting. Students were engaged and took charge of their own learning.

Results indicated the significance of the project as nearly all participating students (98\%) completed all the learning modules by the end of the year. A major factor in this was changing student expectations about music being "school work" through participation and engagement with the project. There was a notable increase from the data captured at the beginning of the year when only 140 students or $32 \%$ said they think they would use Project Music X outside of school time, to half way through the year when the figures indicated that 300 students or $68 \%$ were actively using it outside of school time. This was further increased to 410 students or $93 \%$ by the conclusion of the year. This is not only supported by the steady increase in student interest and engagement (Figure 5), but the fact that many of the students decided to learn an instrument. Regardless of whether this correlation is statistically conclusive or not, it can be implied that there is a clear relationship. This is further supported by the classroom teachers who expressed that not only did they feel supported in using technology in an innovative and multidimensional way, but they could see the immediate value for their students' learning in the clear progress that was made. The students' qualitative comments confirm their engagement in learning music in an authentic and meaningful way.

Similar to other valuable music education interactive online resources, Project Music $X$ has enabled students to build skills in using technology to support the development of music compositions, learning an instrument and participating in workshops. The success of the project so far is largely attributed to the platform it provides for creating, sharing, collaborating and receiving feedback. It is a multidimensional learning environment that harbours metacognition as it is both student centred and self-directed. The opportunity for students to work with elite musicians and experience high quality music performances through partnerships with professional orchestras and bands has developed students' understanding of musical expression and inspired creativity. The benefits of such technology creating opportunities for enhancing quality music education experiences within real-life contexts supports current curricula objectives and the thinking of contemporary society, particularly young people. The importance of such a platform for learning and teaching music education is further amplified by the Australian Arts curriculum due for implementation in 2014 (ACARA, 2012b). A platform such as Project Music $X$ enables accessibility of high quality music education to all students, fulfilling the requirement of all schools to have at least one of the Arts subjects present in their curriculum from Foundation (prep) to Year 10.

Encouragingly, there is wide recognition that the use of technology in music education can create exciting and engaging teaching and learning opportunities (Moore, 1992; McCoy, 2000; Byrne \& MacDonald, 2002; Ruthmann, 2007). Mark and Madura (2010) state that "technology will continue to evolve and music teachers will need to be prepared for a shifting paradigm for music education" (p. 140). In fact, this 
pedagogical change will be true for education as a whole. New technologies have already created learning opportunities that challenge the traditional schooling model, universities and pedagogy:

These new learning niches enable people of all ages to pursue learning on their own terms. People around the world are taking their education out of school into homes, libraries, Internet cafes, and workplaces, where they can decide what they want to learn, when they want to learn, and how they want to learn...Schools have made invaluable contributions to the world's development and we think they will continue to do so well into the future. However, we think it is time that educators and policy makers start to rethink education (Collins \& Halverson, 2009, p. 1).

Project Music $X$ is a successful example of the positive learning and teaching outcomes that can occur when new technologies are embraced in an authentic way.

Further, in addressing the underlying issue of policy change, education and government authorities need to overcome the threats that accompany digital technologies by addressing them rather than dismissing them. It is reasonable to suggest that most young people already know how to bypass school cyber protection measures. Rather than continuing to mystify the cyberworld by blocking sites and preventing access, a need for educating young people is necessary. Allowing access to the cyberworld for the benefits of teaching and learning will not only demystify the unknown, but arm our young with educated choices and the ability to be knowledgeable and skilful users of new technology. Teachers also need to be better informed and will be required to take a more active role in monitoring classroom cyber use. This was achieved very successfully in the case of the project demonstrated in this study. In moving forward and rethinking education in a digital age, school policy and cyber safety strategies need to address educating our young people to empower them. As demonstrated by Project Music X, web 2.0 applications and blended learning not only provide invaluable learning experiences, but they are beneficial for distance learning and schools in remote or rural areas, achieving the aims of the project. Evolving technologies require educational policy change; only then will all students have access to a holistic music education experience facilitated by professional teachers and high quality technological resources that respond to contemporary societal requirements.

\section{References}

Australian Curriculum and Assessment Reporting Authority. (2012a) Information and Communication Technology (ICT) capability. Retrieved from http://www.australiancurriculum.edu.au/General Capabilities/Information-and-Communication-Technology-capability/Introduction/Introduction

Australian Curriculum and Assessment Reporting Authority. (2012b). The arts. Retrieved from http://www.acara.edu.au/arts.html

Avrhami, J. (2010). Educators, trainers can do more with less using 21st century online learning collaboration [Elluminate New: Press release]. Retrieved May 21, 2010 from http://silverscorpio.com/tag/sustainable-models/

Berklee College of Music (2012) Berklee Shares. Retrieved from http://www.berkleeshares.com/

Berners-Lee, T. (1999) Weaving the web. London: Orion Business Books.

Borota, B. (2011). Motivation and learning results in music education related to blended learning. Metodicki obzori, 12(6), 49-59.

Bray, M., Brown, M., \& Green, T. (2004). Technology and the diverse learner: A guide to classroom practice. Thousand Oaks, California: Corwin Press.

Byrne, C., \& Macdonald, R. A. R. (2002). The use of information and communication technology (I\&CT) in the Scottish Music Curriculum: A focus group investigation of themes and issues. Music Education Research, 4(2), 263-273. 
Cain, T. (2004). Theory, technology and the music curriculum. British Journal of Music Education, 21(2), 215-221.

Choi, H., \& Piro, J. (2009). Expanding arts education in a digital age. Arts Education Policy Review, $110(3), 27-33$.

Collins, A., \& Halverson, R. (2009). Rethinking education in the age of technology: The digital revolution and the schools. New York: Teachers College Press.

Collinson, G. (2012). What is The Music Page? themusicpage.com Retrieved from http://www.themusicpage.com/mtvText.php?file=about

Crawford, R. (2007). Authentic learning and digital technology in the music classroom (Unpublished doctoral dissertation). Monash University, Victoria. ]

Crawford, R. (2009a). An Australian perspective: Technology in secondary school music. Journal of Historical Research in Music Education, 30(2), 147-167. Retrieved from http://www.highbeam.com/doc/1G1-204853985.html

Crawford, R. (2009b) Secondary school music education: A case study in adapting to ICT resource limitations. Australian Journal of Education Technology, 25(4), 471-488. Retrieved from http://www.ascilite.org.au/ajet/ajet25/crawford.pdf

Crow, B. (2006). Musical creativity and the new technology. Music Education Research, 8(1), 121-130.

Department of Education and Early Childhood Development. (n.d.). Victorian essential learning standards (VELS). Retrieved from http://www.education.vic.gov.au/school/parents/primary/Pages/vels.aspx

Digolo, B. A., Andang'o, E. A., \& Katuli, J. (2011). E-Learning as a strategy for enhancing access to music education. International Journal of Business and Social Science, 1(11), 135-139.

Dillon, S. C., \& Brown, A. R. (2007). Realising the possibilities of technology in music education research and philosophy. Proceedings of the Fifth International Research in Music Education Conference, Exeter, UK. Retrieved from http://eprints.qut.edu.au/13214/1/13214.pdf

Dillon, T. (2007). Current and future practices: Embedding collaborative music technologies in English secondary schools. In J. Finney \& P. Burnard (Eds.), Music education with digital technology (pp. 117-127). London: Continuum.

Downes, S. (2005). E-learning 2.0. E-Learn Magazine: Education and Technology in Perspective. Retrieved from http://elearnmag.acm.org/featured.cfm?aid=1104968

Dziuban C. D., Hartman J. L., \& Moskal, P. D. (2004). Blended Learning. EDUCAUSE Center for Applied Research, Research Bulletin, 7, 1-12. Retrieved from http://net.educause.edu/ir/library/pdf/ERB0407.pdf

Hitchcock, M. (2008, June). Making music together: The blending of an on-line learning environment for music artistic practice. Paper presented at Creative Industries and Innovation conference, Creating Value: Between Commerce and Commons, Brisbane, Australia.

Hitchcock, M. (2009, November). Vertical integration through blended learning: a whole of program case study. Paper presented at CreateWorld 2009 - Mobile Me: Creativity on the Go, Brisbane, Australia.

Hitchcock, M., Cunio, K., Harvey, L., \& Chircop, D. (2010, November). Crossing boundaries: promoting cross-disciplinary projects in four creative arts faculties. Paper presented at CreateWorld 2010 Working on the Edge: Creativity, Technology and Innovation, Brisbane, Australia. 
Huitt, W. G. (1999). Success in the information age: A paradigm shift. Revision of paper developed for a workshop presentation at the Georgia Independent School Association, Atlanta, Georgia, November 6, 1995. Retrieved from http://www.edpsycinteractive.org/papers/infoage.pdf

Mark, M., \& Madura, P. (2010). Music education in your hands. New York: Routledge

McCoy, P. (2000). Digital technologies in the music classroom. In E. Pontiff(Ed.), Spotlight on technology in the music classroom (pp. 110-112). Reston, VA: MENC

Mills, J., \& Murray, A. (2000). Music technology inspected: good teaching in Key Stage 3. British Journal of Music Education, 17(2), 157-181.

Moore, B. (1992). Music, technology, and an evolving curriculum. NASSP Bulletin, 76, 42-46.

Philharmonia Digital Projects (2012) Philharmoia Orchestra - Projects. Retrieved from http://www.philharmonia.co.uk/explore/projects

Pilzer, P. (1990). Unlimited wealth. New York: Crown Publishing Group.

Radwanick, S. (2009). 2 million more Australians go social in 2009 [Press Release. United States]. Retrieved from http://www.comscore.com/Insights/Press_Releases/2009/8/2_Million_More_Australians_Go_Social_i n_2009

Rosenberg, M. J. (2001). E-learning: Strategies for delivering knowledge in the digital age. McGrawHill. Retrieved from http://books.google.co.ke/books?id=RQ2dAAAAMAAJ

Ruthmann, S. A. (2007). Strategies for supporting music learning through on-line collaborative technologies. In J. Finney \& P. Burnard (Eds.), Music education with digital technology (pp. 131141). London: Continuum.

Southcott, J., \& Crawford, R. (2011) Intersections of the curriculum: Music ICT and Australian music education. Australasian Journal of Educational Technology, 27(1), 122-136. Retrieved from http://www.ascilite.org.au/ajet/ajet27/southcott.pdf

Toffler, A. (1981). The third wave. New York: Bantam Books.

Toffler, A. (1990). Powershift. New York: Bantam Books.

Ullrich, C., Borau, K., Luo, H., Xiaohong, T., Liping, S., \& Ruimin, S. (2008). Why web 2.0 is good for learning and for research: principles and prototypes. Proceedings of the $17^{\text {th }}$ international conference on World Wide Web. Beijing: International World Wide Web Conference (pp. 705-714).

Victorian Curriculum and Assessment Authority. (2009a). Interdisciplinary learning. In Victorian essential learning standards: Level 5 Retrieved from http://ausvels.vcaa.vic.edu.au/Level5

Victorian Curriculum and Assessment Authority. (2009b). Discipline-based learning: The Arts. In Victorian essential learning standards: Level 5 Retrieved from http://vels.vcaa.vic.edu.au/downloads/vels_standards/velsrevlvl5.pdf

Corresponding author: Renée Crawford, renee.crawford@monash.edu

Australasian Journal of Educational Technology (C) 2013.

Please cite as: Crawford, R. (2013). Evolving technologies require educational policy change: Music education for the 21st century. Australasian Journal of Educational Technology, 29(5), 717-734. 